\title{
Assessment of Efficacy of Supraintercondylar and Supracondylar Femur Fractures Treated with Condylar Buttress Plates: A Comparative Study
}

\author{
Yusuf Ali Deoda $^{1}$, Prashant Garhwal ${ }^{2}$

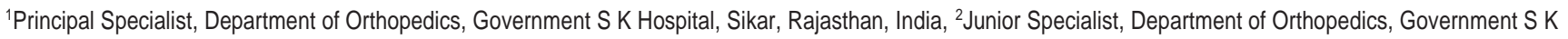 \\ Hospital, Sikar, Rajasthan, India.
}

\section{Abstract}

Background: Treatment of supraintercondylar and supracondylar femur fractures is generally challenging. This study was conducted to compare the efficacy of supraintercondylar and supracondylar femur fractures treated with condylar buttress plates. Subjects and Methods: The study was conducted in Department of Orthopaedics, Government S K Hospital, Sikar, Rajasthan, India. The sample size of 50 patients was selected for the study. Participants of age above 21 were included in the study. Among these in group I, there were 25 participants of supra intercondylar fractures whereas in group II , 25 participants of supra condylar fractures. Statistical analysis was done by using SPSS, version 22 (SPSS, Inc., Chicago, IL) and p<0.05 was considered statistically significant. Results: In our study, 32 were males whereas 18 were females. Supra intercondylar fractures were present in 17 males and 8 females whereas supra condylar fractures were present in 15 males and 10 females. Rate of union occur in 23 cases of Supra intercondylar fractures whereas in 24 cases supra condylar fractures. Complications such as stiffness, varus deformity occur more in supra intercondylar fractures. Time taken for union in both the cases are almost same. Conclusion: Our study concludes that clinical results of supracondylar fractures was better with condylar buttress plates as compared to supra intercondylar fractures.

Keywords: supraintercondylar fracture, supracondylar fracture, condylar buttress plates.

Corresponding Author: Dr. Prashant Garhwal, M.S. (Orthopedics), Junior Specialist, Department of Orthopedics, Government S K Hospital, Sikar, Rajasthan, India.

Received: January 2019

Accepted: February 2019

\section{Introduction}

Distal femur fractures apparently account for not as much of $1 \%$ of all the fractures and include between $4 \%-6 \%$ of all femur fractures. Supra condylar femur fractures occur usually among young persons that involve in high-energy accidents like motor vehicle and motorcycle accidents and sports trauma and older persons, those are osteoporotic. ${ }^{[1]}$ Intra-articular fractures of distal femur account for an enormous surgical challenge. These fractures are difficult to manage and surgical management is usually suggested for a favorable outcome as these are often comminuted and intraarticular. ${ }^{[2]}$ With time pattern of management of supracondylar and inter-condylar femur fractures are changing. Distal femoral fractures are treated using several devices. ${ }^{[3,4]}$ Utilizing multiple techniques $70 \%-85 \%$ cases, good to excellent results were reported for open reduction and internal fixation. ${ }^{[5]}$ The JudeteLetournel screw plate which is an extramedullary hardware is routinely used. ${ }^{[6]}$ From 2000 on, Distal femoral fractures are also fixed with condylar buttress plates. ${ }^{[7]}$ The present study was conducted to assess the efficacy of Supraintercondylar and Supracondylar Femur Fractures Treated with Condylar Buttress Plates.

\section{Subjects and Methods}

The study was conducted in Department of Orthopaedics, Government S K Hospital, Sikar, Rajasthan, Indiaover the period of 1 year. The sample size of 50 patients was selected for the sudy. The study was approved by the ethical committee of institution. All the participants were informed about the study and a written consent was obtained from all the participants. Participants of age above 21 were included in the study. Among these in group I, there were 25 participants of supra intercondylar fractures whereas in group II, 25 participants of supra condylar fractures. Statistical analysis was done by using SPSS, version 22 (SPSS, Inc., Chicago, IL) and $\mathrm{p}<0.05$ was considered statistically significant.

\section{Results}

The sample size of 50 patients was selected for the sudy. Among these in group I, there were 25 participants of supra intercondylar fractures whereas in group II, 25 participants of supra condylar fractures. In our study, 32 were males whereas 18 were females. Supra intercondylar fractures were present in 17 males and 8 females whereas supra condylar fractures were present in 15 males and 10 females. Table 3 shows the clinical outcome of the study. Rate of union occur in 23 cases of Supra intercondylar fractures 
whereas in 24 cases supra condylar fractures. Complications, stiffness, varus deformity only occur in supra intercondylar fractures. Time taken for union in both the cases are almost same.

Table 1: Distribution of gender
\begin{tabular}{|l|l|l|}
\hline Gender & N(\%) & p-value \\
\hline Male & $32(64 \%)$ & $<0.05$ \\
\hline Female & $18(36 \%)$ & \\
\hline Total & $50(100 \%)$ & \\
\hline
\end{tabular}

\begin{tabular}{|c|c|c|c|}
\hline \multicolumn{2}{|c|}{$\begin{array}{l}\text { Supra intercondylar fractures } \\
(25)\end{array}$} & \multicolumn{2}{|c|}{ supra condylar fractures $(25)$} \\
\hline Male & Female & Male & Female \\
\hline 17 & 8 & 15 & 10 \\
\hline
\end{tabular}

Table 3: Clinical outcomes

\begin{tabular}{|l|l|l|}
\hline Variable & $\begin{array}{l}\text { Supraintercondylar } \\
\text { Fracture }\end{array}$ & $\begin{array}{l}\text { Supracondylar } \\
\text { Fracture }\end{array}$ \\
\hline Rate of union & 23 & 24 \\
\hline $\begin{array}{l}\text { Time taken for } \\
\text { union (months) }\end{array}$ & 6 & 5.7 \\
\hline Complications & 1 & 0 \\
\hline Infection & 3 & 2 \\
\hline Stiffness & 2 & 0 \\
\hline Varus deformity & 3 & 0 \\
\hline
\end{tabular}

\section{Discussion}

Fractures of the distal femur account for $6 \%$ of all femur fractures and is clinically challenging. Sufficient mechanical stability is required in the treatment of distal femur fractures; thus, patients should receive early rehabilitation to achieve better clinical outcome. At present, fixation options include nailing systems and plating systems. Intramedullary nailing can be performed in retrograde pattern. Advantages of intramedullary nailing include less extensive dissection, decreased blood loss, and decreased operating time. ${ }^{[8]}$ In our study, 32 were males whereas 18 were females. Supra intercondylar fractures were present in 17 males and 8 females whereas supra condylar fractures were present in 15 males and 10 females. Rate of union occur in 23 cases of Supra intercondylar fractures whereas in 24 cases supra condylar fractures. Complications such as stiffness, varus deformity occur more in supra intercondylar fractures. Time taken for union in both the cases was almost same.

Similar study conducted by Parihar K et al shows that the rate of union was $93.3 \%(\mathrm{n}=28)$ in supra intercondylar fractures and $96.7 \% \quad(n=29)$ in supracondylar fractures. There was no significant difference between the two groups. ${ }^{[9]}$

Weng CJ et al conclude that union rate of supraintercondylar fractures was $90 \%$ and supracondylar fractures was $91.7 \%$. In supraintercondylar group, $16.7 \%$ revealed postoperative varus deformity, whereas none in supracondylar. ${ }^{[10]}$

\section{Conclusion}

Our study conclude that clinical results of supracondylar fractures was better with condylar buttress plates as compared to supra intercondylar fractures.

\section{References}

1. Martin F Hoffmann, Clifford B Jones, Debra L Sietsema, Paul TornettaLll and Scott J Koenig. Clinical Out Comes of Locked Plating of Distal Femoral Fractures In A Retrospective Cohart. Journal of Orthopaedic Surgery and Research.2013; 8: 43.

2. G. N. Kiran Kumar, Gaurav Sharma Kamran Farooque, Vijay Sharma, Ratnav Rattan, Sanjay Yadav, and Devandra Lakhotia . Locking Compression Plate in Distal Femoral Intra Articular Fractures: Our Experience. International Scholarly Research Notice. 2014; 1-5.

3. Foster MC, Komarsamy B, Davison JN. Distal femoral fractures: a review of fixation methods. Injury. 2006;37:97e108.

4. Albert MJ. Supracondylar fractures of the femur. J Am Acad Orthop Surg. 1997;5:163e171.

5. Stover M. Distal femoral fractures: current treatment, results and problems. Injury. 2001;32:SC3e13.

6. Kacou AD, Sie' EJB, Bamba I, et al. Distal femoral fractures. Injury patterns and surgical results [In French]. Rev Afr Chir. 2000;3:68e71.

7. Sie' EJB, Kodo M, Kacou AD, Traore' A, Lambin Y. Condylar buttress plate for distal femoral fractures. A preliminary report. Nig J Orthop Trauma. 2005;4:30e37.

8. Kim J, Kang SB, Nam K, Rhee SH, Won JW, Han HS. Retrograde intramedullary nailing for distal femur fracture with osteoporosis. Clin Orthop Surg. 2012;4(4):307-12. doi:10.4055/cios.2012.4.4.307.

9. Parihar K, Rao A. Assessment of Efficacy of Supra-Intercondylar and Supracondylar Femur Fractures Treated with Condylar Buttress Plates: A Comparative Study. Journal Of Medical Science And Clinical Research.2018;6(8):662-666.

10. Weng CJ, Wu CC, Feng KF, Tseng IC, Lee PC, Huang YC. Comparison of supraintercondylar and supracondylar femur fractures treated with condylar buttress plates. BMC musculoskeletal disorders. 2016 Dec;17(1):413.

Copyright: (c) the author(s), 2019. It is an open-access article distributed under the terms of the Creative Commons Attribution License (CC BY 4.0), which permits authors to retain ownership of the copyright for their content, and allow anyone to download, reuse, reprint, modify, distribute and/or copy the content as long as the original authors and source are cited.

How to cite this article: Deoda YA, Garhwal P. Assessment of Efficacy of Supraintercondylar and Supracondylar Femur Fractures Treated with Condylar Buttress Plates: A Comparative Study. Asian J. Med. Res. 2019;8(1):OR10-OR11.

DOI: dx.doi.org/10.21276/ajmr.2019.8.1.OR4 